\title{
TENDÊNCIAS GLOBAIS E LOCAIS DO ENSINO-APRENDIZAGEM DE INGLÊS NA ATUALIDADE
}

\author{
Marissol Rodrigues Mendonça da Fonseca \\ Mestre em Letras - Linguística - pela Universidade do Estado do Rio de Janeiro (UERJ) \\ Professora do Colégio Pedro II \\ marissolrmfonseca@yahoo.com.br
}

\section{RESUMO}

O presente artigo é parte de uma dissertação de mestrado que teve como objetivo compreender um fenômeno ligado ao ensino de inglês no contexto de uma escola pública. Neste artigo, analisamos a conjuntura atual em relação ao status do ensino-aprendizagem da língua inglesa, em âmbito nacional e global. Para tanto, buscamos compreender qual é o papel dessa língua na atualidade. Por fim, analisamos as tendências para o futuro: quais serão as prováveis transformações que o inglês sofrerá e como essas mudanças impactarão no ensino-aprendizagem da língua.

Palavras-chave: ensino-aprendizagem de inglês, inglês na atualidade; tendências futuras do inglês.

\section{ABSTRACT}

This article is part of a master's thesis that aimed to understand a phenomenon linked to the teaching of English in a public school. We analyze the current situation in relation to the teaching-learning status of the English language, both nationally and globally. To do so, we seek to understand the role of this language in today's world. Finally, we analyze the trends for the future: what probable transformations English will undergo, and how these changes will impact the teaching-learning of the language.

Keywords: teaching-learning of English, English at present, future tendencies of the English language. 


\section{Introdução}

Vivemos atualmente no que se classifica como pós-modernidade. No entanto, há de se considerar que muitos aspectos da modernidade coexistem com a pós-modernidade no presente. Não é possível delimitar períodos históricos com precisão, ainda mais quando estamos inseridos neles. Portanto, é válido dizer que ainda estamos num período de transição entre a modernidade e a pós-modernidade. Segundo Graddol (2006a), esses dois períodos coexistentes estão em constante tensão um com o outro.

Os valores modernos, que possuem um caráter mais fixo (racionalismo, progresso, identidade nacional, monolinguismo), se chocam com a volatilidade das características pós-modernas (mudanças frequentes, complexidade e caos, identidades fluidas, transnacionalismo, multilinguismo). Essa complexa coexistência tem criado paradoxos e contradições que têm afetado diversas esferas de nossas vidas, tanto em âmbito público quanto particular. Consideramos que a constatação dessa tensão e suas consequências possam nos fornecer subsídios para o entendimento do papel do inglês no mundo atual. Retomaremos essa questão mais adiante, mas é necessário que a tenhamos em mente ao analisarmos os fatos a seguir.

Um dado do período em que estamos vivendo é que o inglês se consolidou como a língua franca do mundo. É a única língua do planeta que possui mais falantes não-nativos do que nativos, totalizando dois terços dos falantes desse idioma (LEFFA, 2003). Outro dado é que três quartos de todas as viagens internacionais ocorrem entre países cuja língua oficial não é o inglês, o que sugere uma demanda cada vez maior por uma língua global. Há outros fatores relativos à globalização que têm estimulado a expansão do inglês: a alta mobilidade de pessoas e crescentes ondas imigratórias, a terceirização de 
serviços para países com mão-de-obra mais barata, a revolução comunicacional (novas tecnologias que permitem a comunicação entre pessoas de diferentes pontos do globo), o crescimento das classes médias urbanas, a internacionalização das universidades e consequente mobilidade de pesquisadores, entre outros (GRADDOL, 2006a). Como Leffa (2003, p. 230) pontua, "uma consequência mais imediata da queda das fronteiras geográficas é que mais pessoas começam a falar a mesma língua”.

Diante desse cenário, a busca pelo inglês tem crescido rapidamente, em função da percepção de que não falar a língua hegemônica leva à exclusão. Leffa (2003, p. 231) afirma que "na atualidade, o desconhecimento da língua inglesa não só restringe o acesso à informação a ser recebida, como também limita o alcance da mensagem a ser transmitida". Uma das principais ideias de Bordieu (1991 apud FINARDI, 2016) é que há diferentes formas de capital além do econômico, sendo dois exemplos, o capital cultural (relativo a conhecimentos, habilidades e outras aquisições culturais) e o capital linguístico (referente à capacidade de produzir expressões oportunas para um mercado específico).

Nessa visão, quanto mais capital linguístico um falante tem, mais ele poderá explorar o sistema em benefício próprio para garantir uma vantagem sobre os demais. Dessa forma, adquirir uma língua franca internacional como o inglês é uma forma de ganhar uma vantagem competitiva num mundo globalizado, seja no mercado de trabalho ou na vida social. Daí advém a "febre do inglês": uma busca desenfreada pela língua que tem começado cada vez mais cedo (especialmente em alguns países asiáticos), chegando ao ponto de uma empresa de internet na Coréia do Sul oferecer cursos de inglês para fetos dentro do útero (ADAMS; HIRSCH, 2007).

Atualmente, estima-se que há aproximadamente 1,5 bilhão de aprendizes de inglês no mundo (BENTLEY, 2014). A China é o país que possui o maior número de aprendizes de 
inglês. O governo chinês está introduzindo o idioma cada vez mais cedo nos currículos escolares, nas grandes cidades, o ensino da língua começa no 1으 ano do Ensino Fundamental. Essa tendência tem se manifestado não apenas na China, mas em todo o mundo. Tradicionalmente, as LEs eram introduzidas no ensino secundário (do segundo segmento do Ensino Fundamental em diante), a partir dos 11, 12 anos de idade. Nos anos 1990, o inglês passou a fazer parte do currículo do ensino primário em diversos países e até mesmo da pré-escola em alguns lugares. À medida que muitas nações desejam tornar-se bilíngues, o ensino da língua inglesa passa a ser considerado um componente da educação básica, e não mais como parte do currículo de LEs.

Aos poucos, esse ensino vem perdendo sua identidade como disciplina e se misturando à educação em geral. Um exemplo é o CLIL (Content and language integrated learning), abordagem em que o inglês é ensinado conjuntamente com outras matérias (em outras palavras, é uma forma de ensinar a língua por meio de conteúdos específicos, como matemática, história e biologia). Essa abordagem emergiu como tendência curricular na Europa, facilitada pela natureza multilíngue do continente. Na maior parte dos casos, o CLIL é usado no ensino secundário e depende da introdução e aprendizagem do inglês já na escola primária. Uma das principais dificuldades para implementá-lo é o fato de que os professores de todas as disciplinas devem ter proficiência na língua (GRADDOL, 2006a).

Devido às transformações no uso da língua inglesa na atualidade, outras abordagens vêm surgindo para substituir as metodologias tradicionais. Um exemplo é o Inglês como Língua Franca (ELF - English as a Lingua Franca), que se baseia no rápido crescimento do número de falantes não-nativos da língua que a utilizam para se comunicar com outros não-nativos. Essa abordagem apregoa um ensino de inglês que 
reflita as necessidades e aspirações dessa comunidade de usuários da língua e que facilite a comunicação intercultural (em contraste com os modelos que focalizam a comunicação com falantes nativos). Outra tendência é o Inglês para Jovens Aprendizes (EYL - English for Young Learners), que se fundamenta na ideia de que as crianças têm mais facilidade para aprender línguas do que alunos mais velhos. O ensino do idioma na infância asseguraria aos alunos mais tempo para dominar a língua e daria a eles a base para o CLIL ou para uma aprendizagem por meio do inglês no ensino secundário.

No contexto brasileiro, estima-se que há em torno de 2,5 milhões de pessoas aprendendo inglês atualmente. No entanto, os níveis de proficiência no país são muito baixos, pois apenas $5 \%$ dos brasileiros afirmam possuir conhecimento da língua (BRITISH COUNCIL, 2014). No ranking mundial, Índice de Proficiência em Inglês da empresa Education First, o Brasil ocupou a 40a posição entre 72 países analisados. O país obteve 50,66 pontos, o que caracteriza um nível baixo de proficiência. Um exemplo ilustrativo é o programa Ciência sem Fronteiras, criado pelo governo para estimular a expansão e internacionalização da ciência e tecnologia para aumentar a competitividade brasileira no panorama mundial. Após o envio de estudantes de graduação e pós-graduação a universidade estrangeira em países de língua inglesa constatou-se a falta de proficiência destes no idioma. Fez-se necessário criar um programa subjacente, o Inglês sem Fronteiras, para tentar reverter o problema.

Um estudo realizado pelo Conselho Britânico em 2015 fez um levantamento da atual situação do ensino-aprendizagem de inglês no Brasil. Dentre as principais descobertas estão: quanto maiores os níveis de instrução e renda, maiores são as chances de aprender a língua; muitos jovens acreditam que o inglês faz parte de seu crescimento pessoal; a aprendizagem da língua é considerada um luxo por alguns e como uma 
atividade extracurricular por outros - mais de $60 \%$ dos respondentes justificaram que não aprenderam o idioma porque custa caro (o que parece refletir a percepção de que só se aprende uma língua pagando-se por um curso particular, pois mais de $70 \%$ dos participantes tiveram aulas de inglês no Ensino Fundamental). Outras descobertas incluem uma acentuada correlação entre o inglês e a maior empregabilidade, pois $48 \%$ afirmaram que estudaram a língua para ter mais chances no mercado de trabalho, e $81 \%$ dos que não aprenderam o idioma disseram que o fariam para aumentar as perspectivas de emprego. Além disso, os falantes brasileiros de inglês têm mais confiança em sua habilidade de leitura em comparação às habilidades produtivas (escrita e fala) (BRITISH COUNCIL, 2015).

Em relação ao ensino da língua inglesa em escolas públicas brasileiras, há outro estudo também feito pelo Conselho Britânico em 2015. No Brasil, até recentemente não havia nenhuma lei ou diretriz que definisse a obrigatoriedade do ensino de inglês', e a escolha da língua estrangeira (LE) a ser ensinada ficaria a cargo principalmente dos estados e municípios. Outras questões relativas a esse ensino (tais como carga horária, habilidades a serem trabalhadas e grade curricular) também são decididas nas esferas estaduais e municipais (desde que sigam as diretrizes dos documentos oficiais).

Uma das principais conclusões da pesquisa é que "o ensino do inglês é pouco regulamentado no Brasil e sua oferta apresenta pouca padronização" (BRITISH COUNCIL, 2015). Por não haver uma política nacional específica em relação ao ensino de língua inglesa (ou outras línguas), o cenário do ensino de LEs nas escolas brasileiras é bastante heterogêneo e irregular. Somam-se a esse panorama outros problemas que são comuns a todas as disciplinas, tais como: a localização de muitas escolas em bairros de alta vulnerabilidade social, turmas grandes e heterogêneas, baixas remunerações aos 
professores, falta de políticas de formação continuada. No caso específico do inglês, há mais dificuldades: há poucos professores com formação superior específica em língua inglesa e faltam recursos didáticos/tecnológicos (que, segundo os professores entrevistados têm uma relevância maior no ensino de sua matéria do que em outras).

Devido a essas questões, o nível de inglês ensinado nas escolas é, em geral, muito baixo. Os PCN reconhecem a existência dessas adversidades e consequentemente preconizam que o foco do ensino de LE deve ser na habilidade de leitura. Há ainda uma percepção dos docentes de inglês de uma desvalorização e distanciamento da disciplina, tanto por parte dos alunos quanto pela própria escola. Outra constatação do estudo é que

É necessário pautar uma discussão ampla sobre o papel do ensino do inglês na formação do jovem brasileiro. Os dados indicam um contexto em que o inglês não tem uma função clara, uma vez que não há plano estratégico comum para o aprendizado da língua, a qual tampouco é considerada relevante dentro da base curricular. Enquanto for visto como uma disciplina complementar, o inglês não será desenvolvido de forma adequada nas escolas públicas, o que prejudica a inserção do Brasil em um contexto globalizado (BRITISH COUNCIL, 2015, p. 37).

Se considerarmos que o inglês atualmente desempenha uma função de língua franca global, sendo o idioma mais utilizado para negócios, vida acadêmica e trocas internacionais, a falta de políticas e investimentos governamentais para promover seu ensino pode resultar em um significativo atraso econômico e social para o país. 0 programa Ciência sem Fronteiras, que citamos anteriormente, é um exemplo de que o progresso nacional pode ser impactado pela falta de proficiência na língua. 
Jenkins (2015 apud FINARDI, 2016) cunhou o termo Inglês como Multilíngua Franca (English as a Multilingua Franca) para se referir ao uso da língua em contextos de comunicação multilíngue. Nesses contextos, o inglês seria uma opção de língua de contato, mesmo que não seja necessariamente usado. O foco desse novo termo é o perfil multilíngue dos usuários de inglês, e as outras línguas envolvidas nas interações também são consideradas. Tal conceito desloca o inglês da visão anacrônica de uma agenda imperialista, de uma ameaça às outras línguas, para uma perspectiva progressista, o falante não precisa "escolher" entre sua língua materna ou a língua global, mas simplesmente a utilizar quando necessário como um "recurso móvel”ii para aumentar sua mobilidade social e econômica. Sobre o ensino-aprendizagem do inglês no Brasil, Finardi pontua que

[...] Como nos lembra Blommaert em uma observação sóbria, a globalização gera imensa riqueza para aqueles com os recursos certos, mas também cria imensa miséria para aqueles que não os têm. Nesse sentido, acho que o inglês pode ser visto como uma forma de "recurso móvel" no Brasil e, segundo Finardi (2014), a falta de garantia de ter aulas de inglês de qualidade nas escolas públicas brasileiras cria (ou perpetra) uma lacuna social por meio da qual aqueles que têm condições de estudar inglês em instituições privadas terão esses recursos e se beneficiarão da riqueza criada por eles, enquanto que aqueles que não podem pagar sofrerão com a miséria criada por sua faltaiii (FINARDI, 2016, p. 23, tradução nossa).

Devido ao histórico de regime ditatorial no Brasil, ainda persistem no país algumas barreiras ideológicas em relação à língua inglesa. Leffa (2013) alerta que o Brasil precisa superar esses problemas ideológicos para não correr o risco de se isolar linguisticamente (e consequentemente em aspectos sociais e econômicos). O inglês não pode e nem deve ser visto como a língua dos americanos ou dos britânicos; em outro texto, o autor 
argumenta que "o inglês não é uma língua estrangeira, não pertence aos Estados Unidos, à Inglaterra, ou qualquer outro país de fala inglesa. O inglês pertence ao mundo." (LEFFA, 2006, p. 13). É verdade que não devemos ignorar o passado e esquecer as origens imperialistas/colonialistas da língua. Canagarajah (2013, p. 54, tradução nossa) nos lembra que "[a] língua não é livre de valores"iv; ou seja, não há língua puramente objetiva que não carregue em si as ideologias da sociedade em que foi forjada. No entanto, se nos prendermos a esse histórico, corremos o risco de ficar em séria desvantagem, essa visão pode promover ainda mais desigualdade num país que possui uma das piores distribuições de renda do mundo.

É preciso lembrar que o inglês pode ser usado para colonizar, mas também pode ser usado para descolonizar (LEFFA, 2006). Além disso, também é importante lembrar que, no processo de aprendizagem de uma língua, pode-se modificá-la (e muitas vezes, modifica-se, de fato) (RAJAGOPALAN, 2016). Num contexto mundial globalizado, ensinar e aprender inglês (e também outras LEs) é essencial por diversos fatores: para ter acesso à informação e à educação, promover a circulação de produção acadêmica e informações científicas, internacionalizar a educação em vários níveis, lutar contra a mercantilização da educação (por exemplo, a proliferação de cursos de línguas particulares) (FINARDI, 2016).

Alinhamo-nos a Leffa (2006.), Rajagopalan (2016) e Finardi (2016) em suas propostas de conciliação entre as diferentes visões sobre o ensino de inglês. Primeiro, devemos considerar o inglês como língua internacional (ILI) e como instrumento de solidariedade e transformação coletiva do mundo, pois a comunidade que fala o idioma é mundial. O ILI é uma variedade internacional do inglês e não é veículo de uma única cultura; não é mais controlada por autoridades dos EUA ou Inglaterra, mas sim 
propriedade dos usuários internacionais. Cabe a seus professores encontrar um equilíbrio entre um amor por sua disciplina que pode ser alienante e uma postura excessivamente crítica e rancorosa em relação a ela. E ao invés de ensinar as ditas variedades de prestígio, devem-se levar os aprendizes a se familiarizarem com o maior número de variedades e sotaques possível, para prepará-los para as interações interculturais. Segundo, é necessária uma mudança de política linguística em relação às línguas estrangeiras no Brasil. O inglês deve ser considerado como língua internacional e ensinado como tal.

Dessa forma, o idioma seria obrigatório no ensino básico regular e oferecido concomitantemente a outras LEs, cuja escolha continuaria a critério da comunidade escolar, de acordo com suas necessidades. Essa política permitiria uma maior inserção em um contexto globalizado multilíngue, que exige cada vez mais que saibamos outras línguas que não a materna. De acordo com Gregg Roberts, "o monolinguismo é o analfabetismo do século 21" (CHAMY, 2016). Se é do interesse do Brasil progredir econômica e socialmente, não investir no ensino-aprendizagem de inglês pode se tornar um grande empecilho para o seu futuro.

\section{Tendências para o futuro: inglês ameaçado?}

Assim como a história tende a se repetir num padrão de fluxo e refluxo, o mesmo ocorre com as línguas, num mecanismo circular de expansão e contração. Segundo Leffa (2003, p. 228), nesse momento "as línguas estão em franco processo de retração, com o tempo, e com as fusões que ocorrerão entre elas, a humanidade voltará a falar uma língua que será novamente única sobre a face da terra". Um dado sugestivo é que o latim, que já desempenhou a mesma função de língua franca mundial no passado, entrou em 
declínio após quase mil anos de expansão. Pode-se prever que o mesmo acontecerá ao inglês, mas provavelmente de maneiras diferentes; ao invés de simplesmente considerarmos que os ciclos se repetem e os padrões são recorrentes, é preciso ponderar que eles também evoluem num processo de transformação, que incorpora o novo ao antigo (LEFFA, 2003).

O latim desapareceu, porém, deu origem a diversas outras línguas. Quando uma língua se propaga, ela se modifica. No caso do inglês, que possui mais falantes nãonativos (1,5 bilhão) que nativos (400 milhões), é provável que sua futura direção seja ditada por aqueles que a utilizam como segunda língua ou LE. Fenômenos como codeswitching (quando pessoas se valem de duas ou mais línguas para se comunicar) e o surgimento de línguas mestiças (como o Spanglish e o Franglais) são significativos das mudanças que o inglês vem sofrendo e continuará a sofrer. No entanto, deve-se considerar que não existia globalização quando o latim se fragmentou; o mundo atual se tornou "menor", e há inúmeras oportunidades de contato nos dias de hoje. A globalização e suas consequências atuam como forças centrípetas que impedem a fragmentação completa da língua (CRYSTAL, 2000). Nesse cenário, é necessária uma língua em comum que permita a comunicação internacional, e é o inglês que ocupa esse espaço atualmente e provavelmente continuará a ocupar. Porém, não será o inglês exatamente como o conhecemos.

Uma tendência para o futuro é que as línguas diminuirão em número e se tornarão mais simplificadas. As línguas faladas por comunidades pequenas provavelmente não resistirão; no passado, por exemplo, processos de colonização, urbanização e alfabetização levaram ao desaparecimento de línguas indígenas nativas. Em relação à simplificação, esse fenômeno ocorre quando línguas vão sendo transmitidas para outras 
gerações ou outras comunidades e novas versões vão sendo criadas, com vocabulários menores e gramáticas menos complexas. Segundo McWhorter,

[...] o mundo está testemunhando o nascimento de versões levemente otimizadas de línguas antigas. [...] [Porém], essa simplificação não deve ser tomada como um sinal de declínio. Todas as línguas "otimizadas" continuam sendo línguas completas em todos os sentidos do termov (MCWHORTER, 2015, tradução nossa).

O autor conclui que há um aspecto positivo nessas transformações: o fato de que cada vez mais, pessoas serão capazes de se comunicar em uma língua que elas utilizam e também em suas línguas nativas. À medida que as línguas são otimizadas, torna-se mais fácil aprendê-las. Isso é o que parece estar ocorrendo ao inglês enquanto língua franca: os usuários ao redor do mundo estão adaptando a língua para que ela se adéque às suas necessidades, principalmente no que diz respeito à comunicação intercultural. Segundo Rajagopalan (2016, p. 92, tradução nossa), “[...] a única maneira segura de dominar uma 'língua estrangeira' é 'nativizá-la' de alguma forma”vi . Ou seja, para apropriar-se de fato de uma língua, é necessário transformá-la para que ela atenda às demandas de seus falantes. Não à toa, diversos termos vêm sendo cunhados para descrever esses novos "ingleses": Inglês como Língua Internacional (SMITH, 1983), Inglês como Língua Franca (SEIDLHOFER, 2011), Inglês Mundial (KACHRU, 1983), Inglês como Multilíngua Franca (JENKINS, 2015) (apud FINARDI, 2016).

Assim como as línguas têm se modificado, a forma de aprendê-las também está em processo de transformação, especialmente no caso do inglês. Graddol (2006b, tradução nossa) identifica duas principais mudanças: a idade e as motivações dos aprendizes. $\mathrm{O}$ autor afirma que "[...] o aprendiz de inglês do futuro será diferente daqueles do passado, 
e ele buscará um tipo diferente de inglês, esperando aprendê-lo de maneira que reflitam a tecnologia e os estilos de vida do século $21^{\prime \prime \text { vii }}$. Como dito anteriormente, a aprendizagem do inglês tem começado cada vez mais cedo, e o idioma se transformou num componente central em muitas reformas educacionais, tendo adquirido o status de habilidade básica. $\mathrm{O}$ autor estimou que o número de pessoas aprendendo inglês atingiria seu pico por volta de 2010, com aproximadamente 2 bilhões de aprendizes. Depois do auge, esse número entrará em rápido declínio, caindo para 500,600 milhões em 2050 (GRADDOL, 2006a). Isso porque, à medida que o inglês se consolida como língua internacional e conquista espaço na grade escolar primária como conhecimento básico, cada vez menos pessoas chegarão à adolescência e idade adulta sem dominar a língua. $\mathrm{A}$ tendência será buscar um terceiro e até mesmo um quarto idioma (CHAMY, 2016).

Em relação às motivações, as razões e estímulos para aprender a língua inglesa diferirão daquelas do passado. A globalização tem permitido que pessoas de diferentes nacionalidades se comuniquem, e elas têm se voltado para o inglês como meio de comunicação. Portanto, o principal interesse é em como usar a língua de forma apropriada em ambientes interculturais, sejam os objetivos profissionais, educacionais ou sociais. O modelo do falante nativo perde importância, pois a maior parte da comunicação se dará entre não-nativos; além disso, novas variantes do inglês têm surgido ao redor do globo. Os modos de aprender serão cada vez mais centrados no aluno e no seu estilo de aprendizagem. Em contraste com os tradicionais métodos de ensino (aos quais os alunos deviam se adequar), Graddol afirma que

[...] os aprendizes do futuro esperam poder escolher uma fórmula que se ajuste às suas disposições culturais e psicológicas, ou às suas necessidades particulares naquele momento. Eles, ao invés de seus professores, decidirão como, o que e 
quando eles aprenderão. Os sites fornecerão o tipo de apoio necessário para os aprendizes traçarem um caminho através do material e monitorar seu progresso viii (GRADDOL, 2006b, tradução nossa).

As tecnologias têm permitido um nível cada vez maior de independência no processo de aprendizagem, uma vez que elas permitem que o inglês chegue ao aluno, ao invés de o aluno ter de buscá-lo. No entanto, isso não significa que o presencial poderá ser completamente substituído pelo virtual, as tecnologias facilitarão e ampliarão a comunicação entre pessoas, entre professores e alunos, mas não a substituirão. Por exemplo, no contexto brasileiro, a maioria dos respondentes de uma pesquisa afirmou preferir cursos de inglês presenciais àqueles que são totalmente a distância (BRITISH COUNCIL, 2014). A tendência é que a tecnologia tenha um papel significativo na educação por intermédio de blended learning ${ }^{i x}$ (aprendizagem híbrida), como complemento para a educação presencial.

Por meio da análise do contexto atual, buscamos fazer previsões sobre o futuro do inglês. Porém, como o próprio nome já diz, previsões podem acontecer ou não, e o futuro da língua dependerá de uma série de possíveis encaminhamentos. Retomamos aqui a questão do conflito entre modernidade e pós-modernidade e as contradições que esse momento de transição ocasiona. Por exemplo, o inglês, visto por muito tempo como um projeto neoimperialista, entra em ascensão ao mesmo tempo em que os Estados Unidos perdem progressivamente seu prestígio internacional. A aprendizagem do idioma é fortemente encorajada pelos governos e por pais de alunos em busca de uma vantagem competitiva, num momento em que o inglês já não se configura mais como um diferencial, mas sim como um componente básico da educação. À medida que o inglês global se afasta cada vez mais da classificação como língua estrangeira e se coloca como 
habilidade básica, mais necessidade por outras línguas ele impulsiona. Quanto mais vantagem o idioma traz para seus aprendizes, mais desigualdade ele acarreta para aqueles que não o dominam. Dentre tantos paradoxos, uma questão parece clara: não investir no aprendizado do inglês num contexto altamente globalizado e multicultural como o que nos encontramos agora é um risco, tanto em âmbito nacional quanto pessoal.

\section{Referências}

ADAMS, J.; HIRSCH, M. English for everyone. Newsweek International, [S.I.], Aug. 20, 2007. Disponível em: <http://www.highbeam.com/doc/1G1-167580602.html>. Acesso em: 10 set. 2014.

BRASIL. Ministério da Educação. Base nacional comum curricular. Disponível em: <http://basenacionalcomum.mec.gov.br/\#/site/base/o-que>. Acesso em: 2 dez. 2016. BENTLEY, J. Report from TESOL 2014: 1.5 Billion English Learners Worldwide. Disponível em: <https://www.internationalteflacademy.com/blog/bid/205659/report-from-tesol2014-1-5-billion-english-learners-worldwide>. Acesso em: 9 dez. 2016.

BRITISH COUNCIL. Learning English in Brazil: Understanding the aims and expectations of the Brazilian emerging middle classes. São Paulo, 2014. 29 p. English in Brazil. São Paulo, 2015a. 57 p. . O ensino de inglês na educação pública brasileira. São Paulo, 2015b. 42 p.

CANAGARAJAH, S. Navigating language politics: a story of critical práxis. In: NICOLAIDES, C.; SILVA, K. A.; TÍLIO, R.; ROCHA, C. CH. (Orgs.). Política e políticas linguísticas. Campinas: Pontes. 2013. p. 43-61.

CHAMY, C. H. Falar só um idioma é o analfabetismo do século 21? BBC Brasil: [S.I.], 08 maio 2016. Disponível em: 
<http://www.bbc.com/portuguese/geral/2016/05/160502_monolinguismo_analfabetism o_rb>. Acesso em: 15 dez. 2016.

CRYSTAL, D. The future of English as a world language. Concord, [S.I.], p. 4-7, Jan. 2000. Disponível em: <www.davidcrystal.com/?fileid=-4037>. Acesso em: 23 nov. 2016.

FINARDI, K. Globalization and English in Brazil. In: FINARDI, K. (Org.). English in Brazil: views, policies and programs. Londrina, PR: Eduel - Editora da Universidade Estadual de Londrina, 2016. p. 13-32.

GRADDOL, D. English next: Why global English may mean the end of 'English as a foreign language'. British Council, 2006a. Disponível em: <http://www.britishcouncil.org/learningresearch-english-next.pdf.>. Acesso em: 24 abr. 2015.

. English and the future. Reino Unido: BBC online, 2006b. Disponível em:

<http://www.bbc.co.uk/worldservice/learningenglish/radio/specials/1720_ten_years/pag e9.shtml>. Acesso em: 7 mar. 2013.

LEFFA, V. J. Língua estrangeira hegemônica e solidariedade internacional. In: KARWOSKI, A. M.; BONI, V. F. (Orgs.). Tendências contemporâneas no ensino de inglês. União da Vitória, PR: Kaygangue, 2006. p. 10-25.

O ensino de inglês no futuro: da dicotomia para a convergência. In: STEVENS, C. M. T.; CUNHA, M. J. C. (Orgs.). Caminhos e colheita: ensino e pesquisa na área de inglês no Brasil. Brasília: Editora UnB, 2003. p. 225-250.

. Prefácio. In: NICOLAIDES, C.; SILVA, K. A.; TíLIO, R.; ROCHA, C. CH. (Org .). Política e políticas linguísticas. Campinas, SP: Pontes, 2013. p. 7-10.

MCWHORTER, J. H. What the world will speak in 2115. The Wall Street Journal, Jan. 2, 2015. Disponível em: <http://www.wsj.com/articles/what-the-world-will-speak-in-21151420234648>. Acesso em: 4 jan. 2017.

RAJAGOPALAN, K. English in Brazil: dealing with a political hot potato. In: FINARDI, K. (Org.). English in Brazil: views, policies and programs. Londrina, PR: Eduel - Editora da Universidade Estadual de Londrina, 2016. p. 79-96. 


\begin{abstract}
'Em fevereiro de 2017, o senado brasileiro aprovou a reforma do ensino médio, através da medida provisória 746/2016. Dentre as mudanças propostas, "a reforma torna o inglês obrigatório desde o $6^{\circ}$ ano do Ensino Fundamental e no Ensino Médio, não necessariamente nos três anos. Os sistemas de ensino poderão ofertar outras línguas estrangeiras se assim desejarem" (BRASIL, 2016). A obrigatoriedade do inglês é justificada pelo fato de que "a língua inglesa é a mais disseminada e a mais ensinada no mundo inteiro" e também pelo fato dessa língua ser necessária para a inserção no mundo do trabalho (BRASIL, 2016).No entanto, acreditamos que a obrigatoriedade por si só não garantirá a oferta regular e de qualidade do idioma. A eficácia dessa medida ainda está por ser vista.
\end{abstract}

ii Segundo Blommaert, recursos móveis são "repertórios que as pessoas possuem e empregam", tais como registros, variedades, sotaques, gêneros e habilidades (2010 apud FINARDI, 2016, p. 23, tradução nossa).

iii Texto original: "As Blommaert reminds us in a sobering remark, globalization generates immense wealth for those with the right resources but it also creates immense misery for those who lack them. In that sense, I think English can be viewed as a form of "mobile resource" in Brazil and according to Finardi (2014), the lack of guarantee to have quality English classes in Brazilian public schools creates (or perpetrates) a social gap whereby those who can afford to study English in private language institutes will have those resources and benefit from the wealth created by them whereas those who cannot afford it will suffer the misery created by their lack".

iv Texto original: “[...] language is not value free".

v Texto original: "[...] the world is witnessing the birth of lightly optimized versions of old languages. [...] This streamlining should not be taken as a sign of decline. All of the 'optimized' languages remain full languages in every sense of the term $[\ldots]$ ".

vi Texto original: “[ [...] the only sure way of attaining mastery over a 'foreign' language is by 'nativising' it in some sense".

vii Texto original: "[...] the English learner of the future will be different from those of the past, will be looking for a different kind of English and will expect to learn it in ways which reflect the technology and lifestyles of the 21 st century".

viii Texto original: "[...] future learners will expect be able to choose a formula which suits their cultural and psychological dispositions, or their particular needs at that moment. They, rather than their teachers, will decide how, what and when they will learn. Websites will provide the kind of support needed by learners to chart a pathway through the material and monitor progress".

${ }^{\text {ix }}$ Segundo Staker \& Horn (2012), blended learning pode ser definido como "um programa de educação formal que mescla momentos em que o aluno estuda os conteúdos e instruções usando recursos on-line, e outros em que o ensino ocorre em uma sala de aula, podendo interagir com outros alunos e com o professor. Na parte realizada on-line, o aluno dispõe de meios para controlar quando, onde, como e com quem vai estudar. [...] No caso do blended learning, o conteúdo e as instruções devem ser elaborados especificamente para a disciplina ao invés de usar qualquer material que o aluno acessa na internet" (apud VALENTE, 2014).

Recebido em 14 de março de 2018.

Aceito em 6 de maio de 2018. 